\title{
Relationship between Religiosity and Citizenship Behaviours in Organizations: Empirical Evidence from Selected Organisations in Lagos State
}

\author{
Elizabeth I. Olowookere ${ }^{1}$ \\ Kayode A. Oguntuashe 2 \\ Olujide A. Adekeye ${ }^{1}$
}

${ }^{1}$ Department of Psychology, College of Leadership Development, Studies, Covenant University, Ota, Nigeria

${ }^{2}$ Department of Psychology, National Open University, Nigeria

Email: elizabeth.olowookere@covenantuniversity.edu.ng; kayode.oguntuashe@gmail.com; jide.adekeye@covenantuniversity.edu.ng

\author{
Doi:10.5901/mjss.2016.v7n4p
}

Abstract

Religiosity may be considered as a fundamental trait that defines Nigerians as a people. Although it is a concept that underlies all aspects of human behaviours, its impact on employees' behaviours has been underestimated in the workplace. Consequently, the importance of organisational citizenship behaviours (OCB) to organisational effectiveness necessitated the investigation of the relationship between religiosity and OCB. It was hypothesized that the dimensions of religiosity will predict the demonstration of OCB among employees in Nigeria. This study adopted the ex post facto research design and systematic sampling technique. Questionnaire was administered to 359 employees selected from four sectors of the Nigerian economy. The findings revealed a positive relationship between intrinsic religiosity and the three dimensions of OCB: intrinsic religiosity and dutifulness $(r=.182, p<0.01)$; intrinsic religiosity and organisational involvement $(r=.170, p<0.01)$ and intrinsic religiosity and interpersonal relationship ( $r=.146, p<0.01)$. Conversely, a negative correlation was found between extrinsic religiosity and dutifulness $(r=-.136, p<0.01)$; extrinsic religiosity and organisational involvement $(r=-.122, p<0.05$; and a positive correlation between extrinsic religiosity and interpersonal relationship $(r=.137, p<0.01)$. The result further revealed that intrinsic and extrinsic religiosity jointly predicted OCB $\left(R^{2}=.050, F(2,356)=9.303, p<.01\right)$. However, only the intrinsic religiosity dimension significantly contributed to employees' demonstration of OCB $(\beta=.223, p<.01)$; extrinsic religiosity did not make significant contribution to employees' demonstration of OCB $(\beta=-.036, p>0.05)$. It was concluded that the employees' intrinsic religiosity positively impact their demonstration of OCB in the workplace. Consequently, this study recommended management support of intrinsic religiosity within the purview of established work ethics.

Keywords: Intrinsic Religiosity, Extrinsic Religiosity, Organisational Citizenship Behaviours, Nigeria

\section{Introduction}

Religion has been adjudged as a critical aspect of one's self-concept (Kutcher, Bragger, Rodriguez-Srednicki \& Masco, 2010). It may be described as the belief in and reverence for a divine being as the core of one's existence. Religion defines and regulates human behaviour in different contexts depending on their level of commitment and adherence to its principles. The strength of one's commitment to the principles of his or her religion is measured in terms of religiosity. Religiosity refers to individuals' identification with and commitment to the values and principles of a religion. Although it underlies all aspects of human behaviours, religiosity has been underestimated in the workplace.

The work behaviours demonstrated by employees are central to organisational survival and success (Jahangir, Akbar \& Haq, 2004). Every organisation requires employees' demonstration of positive work behaviours for its continuous improvement and relevance. Organ (1988) labelled this set of behaviours as organizational citizenship behaviours (OCB). These behaviours are demonstrated when employees voluntarily and devotedly put up their utmost performances in the pursuit of organisational effectiveness. OCB are neither included in employees' job description, nor directly recognized by organisations' formal reward system, but in aggregate promotes the effective functioning of an organisation (Organ, 1988).

Allameh, Amiri and Asadi (2011) suggested that human behaviours are reflections of their beliefs, expectations, values and other mental perceptions. Similarly, Olowookere (2014) described OCB as the behavioural demonstration of employees' values, conviction and emotional disposition towards their organisations. Also, Ueda (n.d) noted that 
employees' interpretation and execution of job roles are often based on their religious affiliations and beliefs. These claims suggest a connection between employees' religiosity and their work behaviours. Consequently, an empirical investigation of the relationship between religiosity and OCB is very crucial.

\subsection{Statement of the Objectives}

i. To examine the relationship between the dimensions of religiosity and the dimensions of organisational citizenship behaviours.

ii. To establish intrinsic religiosity and extrinsic religiosity as predictors of organisational citizenship behaviours.

\subsection{Research Hypotheses}

i. Dimensions of religiosity will be positively related to the dimensions of organisational citizenship behaviours.

ii. Intrinsic religiosity and extrinsic religiosity will jointly and separately predict organisational citizenship behaviours.

iii. Intrinsic and extrinsic religiosity will jointly and separately predict the dimensions of organisational citizenship behaviours.

\section{Literature Review}

\subsection{Religiosity}

Different religions have prescribed behaviour patterns for their adherents; these behaviour patterns mostly align with acceptable and ethical behaviours in the society and across contexts (Roundy, 2009; Othman \& Hariri, 2012). Religiosity is the expression of the value attached to one's faith (Park \& Smith, 2000). It is the extent to which an individual is devoted to the principles of his/her religion. This is often demonstrated in knowledge quest, frequency of worship, and strict adherence to the creeds of the religion.

Several dimensions of religiosity have been identified by different researchers to indicate individuals' disposition to their religion (Holdcroft, 2006). Allport and Ross (1967) identified the two dimensions of religiosity to include extrinsic religiosity and intrinsic religiosity. These dimensions were proposed as mutually exclusive. Extrinsically religious individuals are involved in religious activities to satisfy specific needs in their lives. Religiosity serves utilitarian purpose for the extrinsically religious individual; they use religion as means to an end. Conversely, intrinsically religious individuals are committed to their religion. They have internalized the values and principles of their religion to the extent that they become the core of their existence. These individuals demonstrate their religious beliefs and convictions as a lifestyle. Extrinsic religiosity is mainly cognitive in the sense that it portrays the individual as a rational thinker weighing the benefits of his/her religion and using such to their advantage. On the other hand, intrinsic religiosity is basically affective in the sense that it portrays the individuals' emotional attachment to the values and beliefs of their religion.

The word 'spirituality' is often used interchangeably with religiosity. It refers to the stimulating force that inspires a person toward purposes that are beyond him/her and that give his/her life meaning and direction (McKnight, 1984, cited in Marschke, Preziosi \& Harrington, 2008). Dale (1991) as cited in Marschke et al (2008) defined spirituality as human striving for the transforming power present in life; the attraction and movement of the human person toward the divine. Accordingly, spirituality may be described as individual's subjective values that increase intimacy with God. The definition of spirituality is consistent with the assumptions of intrinsic religiosity, the selfless devotion to one's religious beliefs and values with the goal of being in harmony with God. Like intrinsic religiosity, spirituality is affective in nature because it appeals to individuals' emotions and values. In corroboration, Moore and Casper (2006) noted that spirituality is generally viewed as some internal substance, belief, attitude, or emotion that influences people's behaviour. Similarly, Mitroff and Denton (1999) asserted that spirituality is the basic feeling of being connected with one's complete self, others, and the entire universe. Therefore, spirituality is used to denote intrinsic religiosity in this study.

\subsection{Organisational citizenship behaviours (OCB)}

Organisational citizenship behaviours were referred to as extra-role behaviours (Belogolovsky \& Somech, 2010; Khalid, Jusoff, Hassan, Ismail, Kassim \& Rahman, 2009). According to Bateman and Organ (1983), extra-role behaviours are behaviours that improve the overall organisational effectiveness and goodwill. These are voluntary and innovative 
behaviours demonstrated by employees as a show of commitment to the achievement of organisational goals. Conversely, in-role behaviours are the prescribed duties of the employees; they represent employees' compliance with organisation's expectations.

Originally, Smith, Organ and Near (1983) conceived OCB as having two dimensions: altruism and generalized compliance. Altruism involves helping behaviours within organisational context; and generalized compliance involves strict adherence to organisational rules and policies. Furthermore, Organ (1988) reconceptualised the OCB dimensions to include: altruism, conscientiousness, courtesy, civic virtue and sportsmanship. The conscientiousness dimension refers to work behaviours that exceed required standards of performance and employees' voluntary adherence to organisational rules and policies. According to Organ (1990), sportsmanship suggests employees' voluntary tolerance and favourable disposition to the unavoidable inconveniences and impositions of work. The dimension of courtesy includes behaviours that show consideration for others when taking work-related decisions; and civic virtue consist of behaviours that show employees' identification with the organisation through their involvement.

Williams and Anderson (1991) regrouped these dimensions into behaviours directed at specific individuals in the organisation, such as courtesy and altruism (OCBI) and behaviours directed at the organisation as a whole, such as conscientiousness, sportsmanship and civic virtue (OCBO). OCBI contribute indirectly to organisational effectiveness (Williams \& Anderson, 1991; Lee \& Allen, 2002) while OCBO is directly beneficial to the organisation without actions aimed specifically at individuals. In the Nigerian context, employees often execute their in-role duties through forced compliance. Therefore, these in-role duties are considered citizenship behaviours when demonstrated voluntarily and devotedly by employees. In words of Katz and Kahn (1966), this is called dependable role performance. OCB in the Nigerian context may be considered to be a combination of dependable role performance and extra role behaviours. Consequently, Olowookere and Adejuwon (2015) proposed OCB in Nigeria as a three dimension construct. These dimensions include Organisational Involvement, Dutifulness and Interpersonal Relationship. Figure 1 illustrates this:

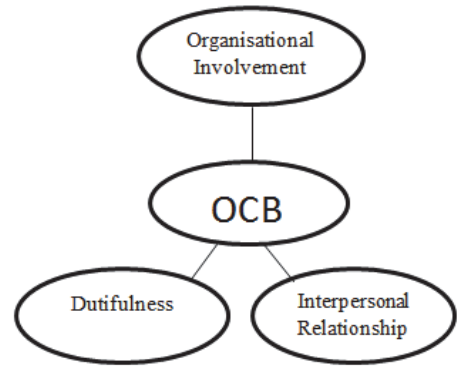

Fig1: A three dimension model of organisational citizenship behaviour

The organisational involvement dimension comprises all forms of employee behaviours targeted at promoting organisational effectiveness and a positive organisational image. These behaviours were labelled as organisational citizenship behaviour directed at the organisation (ОСBO) by Williams and Anderson (1991), civic virtue and sportsmanship by (Organ, 1988). The dutifulness dimension consists of all behaviours that reflect employees' voluntary adherence to organisational rules, work procedures and standards. It incorporates all behaviours indicative of generalized compliance (Smith et al, 1983), conscientiousness (Organ, 1988), dependable role performance and innovative and spontaneous behaviours (Katz, 1964; Katz \& Kahn, 1966). Finally, the interpersonal relationship dimension comprises helping behaviours aimed at fostering cooperation and improved performance among employees in organisations. Williams and Anderson (1991) described these behaviours as organisational citizenship behaviour targeted towards individuals (OCBI). These behaviours are similar to the altruism and courtesy dimensions of Organ (1988).

\subsection{Religiosity and Organisational Citizenship Behaviours}

Past studies suggested a link between religiosity and OCB. For instance, Khalid, Rahman and Madar (2013) examined the role of religiosity on organisational citizenship behaviour among 237 undergraduates from an institution of higher learning located in the north of Peninsular, Malaysia. They found that intrinsic religiosity $(\beta=0.24, P<0.01)$ was a significant predictor of OCBO, while extrinsic religiosity $(\beta=0.29, P<0.01)$ was a significant predictor of OCBI. McCrae 
(2002) associated religiosity with agreeableness which refers to behaviours that cooperate with others and exude selflessness. Morgan (2005) cited in Roundy (2009) observed that individuals experience increasing desire to incorporate their religious perspective into their work. Similarly, King and Williamson, (2005) noted that individuals experience a desire to express their religious and spiritual beliefs at work. Religiosity has been linked with ethical decision-making in organisations (Fernando \& Jackson, 2006; Weaver \& Agle 2002).

McGhee and Grant (2008) reported that spiritual individuals in the workplace have the tendency to demonstrate enhanced teamwork, greater kindness \& fairness, increased awareness of other employees' needs, increased honesty and trust within their organisations, higher incidences of organisational citizenship behaviour, express more servant leader behaviour, perceive the ethical nature of business issues more clearly and are more sensitive to corporate social performance. Affeldt and MacDonald (2010) found that spirituality in general is significantly associated with job satisfaction, work ethic, organisational commitment and organisational citizenship behaviour. Also, Marschke, et al (2008) reported a significant relationship between an organisation's spiritual culture and its profitability; companies that encourage workplace spirituality were found to enjoy increased employee retention and organisational profitability.

Rastgar, Zarei, Davoudi and Fartash (2012) investigated link between workplace spirituality, organisational citizenship behaviour and job performance among 300 employees in 47 branches of Iran Insurance in Babol, Iran. The link between research variables was tested using the SEM technique. The result revealed that workplace spirituality has a significant positive influence on organisational citizenship behaviour ( $t=7.16, p<.05$ ); workplace spirituality has a significant positive influence on job performance $(t=2.71, p<.05)$; and organisational citizenship behaviour has a significant positive influence on job performance $(t=2.60, p<.05)$.

\section{CONCEPTUAL MODEL}

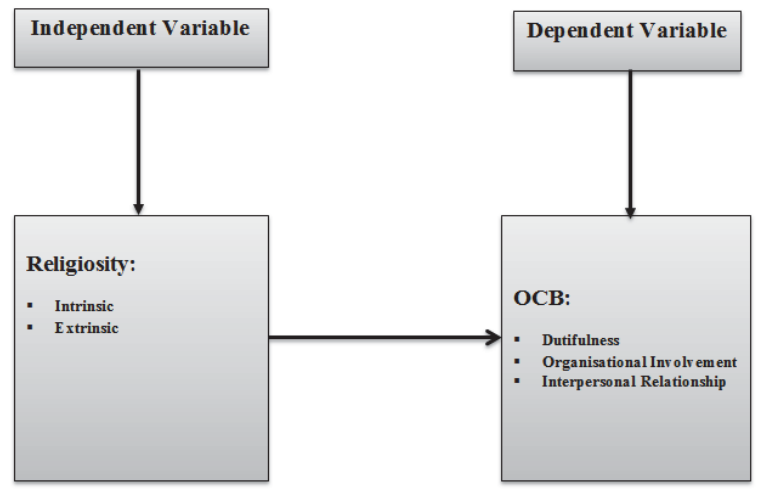

\section{Method}

The research design employed in this study is the ex-post facto design. This is because the proposed relationship between the variables of interest had occurred prior to this study. The health sector, telecommunications sector, education sector and the banking sector were selected in this study based on the suggestions that they are high OCBdemanding sectors (Farooqui 2012; Obamiro, Ogunnaike \& Osibanjo, 2014). The systematic sampling technique was used to select the seventeen (17) organisations sampled from these sectors. This is a statistical method involving the selection of elements from an ordered sampling frame. Using the formula:

$$
k=\frac{N}{n}
$$

Where $n$ is the chosen sample size, and $N$ is the population size.

From the sampling frame, a starting point was chosen at random, and choices thereafter were at regular intervals. Five (5) secondary schools, three (3) banks, three (3) telecommunication companies and six (6) hospitals were selected to participate in this study from an ordered list of three hundred and forty-six (346) registered secondary schools in Lagos state; an ordered list of eighty-seven (87) registered members of Association of Telecommunication Companies of Nigeria (ATCON); an ordered list of twenty-one (21) commercial banks and an ordered list of the ninety- six (96) hospitals. The participants consists of all consenting non-managerial employees from the selected organisations. 
Four hundred (400) questionnaires (one hundred (100) for each sector) were administered to consenting participants. However, only three hundred and fifty-nine (359) duly completed questionnaires were analyzed for the study. The participants of this study were non-managerial employees between the ages of 19 and 59 years. Forty-two percent $(42 \%)$ of the participants were male; fifty-six percent (56\%) were female while the remaining two percent (2\%) did not indicate their gender. Teachers accounted for $28 \%$ of the total sample, health workers constituted $28 \%$, telecom staff $16 \%$ and bankers $28 \%$.

The instruments used in this study include adapted Religious Orientation Scale (ROS) and Organisational Citizenship Behaviour Scale (OCBS). ROS is a validated 20 item measure of religious orientation developed by Allport and Ross (1967). This scale has two sub scales: extrinsic religious orientation with 11 items and the intrinsic religious orientation with 9 items measured on a 5 -point Likert format (1= strongly disagree, $5=$ strongly agree) with scores ranging from $11-55$ and 9 - 45 respectively. The intrinsic religiosity dimension has a Cronbach alpha of .76 while the extrinsic religiosity dimension has a Cronbach alpha of 82 .

The OCBS was developed by Olowookere and Adejuwon (2015); it is a 30 item scale with a Cronbach alpha of .81. The three subscales of OCBS are Interpersonal Relationship, Dutifulness, and Organisational Involvement. The Dutifulness sub-scale has 9 items with Cronbach alpha of .74; the Interpersonal Relationship sub-scale has 12 items with Cronbach alpha of .75 and the Organisational Involvement sub-scale has 9 items with Cronbach alpha of .84. The OCBS is scored on a five point likert format ranging from 4 to 0 , where Always $=4$, Often $=3$, Occasionally $=2$, Rarely $=1$ and Never $=0$.

\section{Analyses and Results}

H1. Dimensions of religiosity will be positively related to the dimensions of organisational citizenship behaviours.

Table 1 revealed a positive relationship between intrinsic religiosity and the three dimensions of OCB: intrinsic religiosity and dutifulness $(r=.182, p<0.01)$; intrinsic religiosity and organisational involvement $(r=.170, p<0.01)$ and intrinsic religiosity and interpersonal relationship $(r=.146, p<0.01)$. This implies that the more intrinsically religious employees are, the more dutiful, the more organisationally involved and the better the quality of their interpersonal relationships. On the other hand, a negative relationship was found between extrinsic religiosity and dutifulness ( $r=-.136$, $p<0.01)$; extrinsic religiosity and organisational involvement $(r=-.122, p<0.05)$; but a positive relationship was found to exist between extrinsic religiosity and interpersonal relationship $(r=.137, p<0.01)$. By implication, the more extrinsically religious employees are, the less dutiful, less organisationally involved but the better the quality of their interpersonal relationships.

Table 1: Correlation Matrix showing the relationship among the variables of study

\begin{tabular}{lccccc}
\hline Variables & $\mathbf{1}$ & $\mathbf{2}$ & $\mathbf{3}$ & $\mathbf{4}$ & $\mathbf{5}$ \\
\hline 1. OCBD & 1 & & & & \\
2. OCBOI & $.471^{\star *}$ & 1 & & & \\
3. OCBIR & $.322^{\star *}$ & $.175^{\star \star}$ & 1 & & \\
4. RELE & $-.136^{\star *}$ & $-.122^{\star}$ & $.137^{\star *}$ & 1 & \\
5. RELI & $.182^{\star *}$ & $.170^{\star \star}$ & $.146^{\star \star}$ & .085 & 1 \\
\hline
\end{tabular}

Correlation is significant at ${ }^{*} p<.05$ and ${ }^{* *} p<.01$

H2. Intrinsic religiosity and extrinsic religiosity will jointly and separately predict organisational citizenship behaviours.

The result in Table 2 revealed that intrinsic and extrinsic religiosity jointly accounted for $5 \%$ variance in organisational citizenship behaviours $\left(R^{2}=.050, F(2,356)=9.303, p<.01\right)$. Although intrinsic religiosity contributed positively to organisational citizenship behaviours $(\beta=.223, p<.01)$, extrinsic religiosity did not significantly contribute to the variance in organisational citizenship behaviours $(\beta=-.036, p>0.05)$. This suggests that the variance in organisational citizenship behaviours was mainly determined by intrinsic religiosity. 
Table 2: Multiple regression analysis showing the joint and separate prediction of intrinsic religiosity and extrinsic religiosity on organisational citizenship behaviour

\begin{tabular}{|c|c|c|c|c|c|c|c|}
\hline Model & $R^{2}$ & $\begin{array}{c}\text { Adjusted } \\
R^{2}\end{array}$ & $\beta$ & $\mathrm{F}$ & $\mathbf{P}$ & $t$ & Sig. \\
\hline 1. (Constant) & & & & & & 16.812 & .000 \\
\hline Intrinsic religiosity & .050 & .044 & .223 & 9.303 & $<.01$ & 4.301 & .000 \\
\hline Extrinsic religiosity & & & -.036 & & & -.697 & .486 \\
\hline
\end{tabular}

a. Dependent variable: organisational citizenship behaviour

b. Predictors: (constant) intrinsic religiosity, extrinsic religiosity

H3. Intrinsic and extrinsic religiosity will jointly and separately predict the dimensions of organisational citizenship behaviours.

The result in Table 3 revealed that intrinsic and extrinsic religiosity jointly accounted for $5.6 \%$ variance in dutifulness $\left(\mathrm{R}^{2}=.056, \mathrm{~F}(2,356)=10.558, \mathrm{p}<.01\right)$. Furthermore, intrinsic religiosity was found to positively contribute to the variance in dutifulness $(\beta=.194, p<.01)$; while extrinsic religiosity was found to contribute negatively to the variance in dutifulness ( $\beta=-.152, p<.01)$. This implies that one standard deviation increase in intrinsic religiosity will result in .194 (in standard deviation unit) increase in dutifulness. Likewise, one standard deviation increase in extrinsic religiosity will result in -.152 (in standard deviation unit) decrease in dutifulness.

Table 3: Stepwise regression analysis showing intrinsic religiosity and extrinsic religiosity on Dutifulness

\begin{tabular}{|c|c|c|c|c|c|c|c|c|}
\hline Model & $R^{2}$ & $\Delta \mathbf{R}^{2}$ & $\begin{array}{c}\text { Adjusted } \\
R^{2}\end{array}$ & B & $\mathbf{F}$ & $\mathbf{P}$ & $\mathrm{T}$ & Sig. \\
\hline 1. (Constant) & .033 & & & & & & 13.282 & .000 \\
\hline Intrinsic Religiosity & & & .030 & .182 & 12.162 & & 3.487 & .000 \\
\hline 2. (Constant) & & .023 & & & & $<0.01$ & 13.449 & .000 \\
\hline Intrinsic Religiosity & .056 & & .051 & .194 & 10.558 & & 3.762 & .000 \\
\hline Extrinsic Religiosity & & & & -.152 & & & -2.948 & .003 \\
\hline
\end{tabular}

a. Dependent Variable: Dutifulness

b. Predictors in the model: (constant), Intrinsic religiosity

c. Predictors in the model: (constant), Intrinsic Religiosity, Extrinsic Religiosity

The result in Table 4 revealed that intrinsic and extrinsic religiosity jointly accounted for $4.8 \%$ variance in organisational involvement $\left(R^{2}=.048, F(2,356)=8.945, p<.01\right)$. Also, intrinsic religiosity was found to positively contribute to organisational involvement $(\beta=.182, p<.01)$; while extrinsic religiosity was found to contribute negatively to the variance in organisational involvement $(\beta=-.138, p<.01)$. This implies that one standard deviation increase in intrinsic religiosity will culminate in .182 (in standard deviation unit) increase in organisational involvement. Likewise, one standard deviation increase in extrinsic religiosity will result in -.138 (in standard deviation unit) decrease in organisational involvement.

Table 4: Stepwise regression analysis showing intrinsic religiosity and extrinsic religiosity on organisational involvement

\begin{tabular}{|c|c|c|c|c|c|c|c|c|}
\hline Model & $R^{2}$ & $\Delta \mathbf{R}^{2}$ & $\begin{array}{c}\text { Adjusted } \\
R^{2}\end{array}$ & $\beta$ & $F$ & $P$ & $T$ & Sig. \\
\hline $\begin{array}{l}\text { 1. (Constant) } \\
\text { Intrinsic Religiosity }\end{array}$ & .029 & .019 & .026 & .170 & 10.686 & & $\begin{array}{l}19.968 \\
3.269\end{array}$ & $\begin{array}{l}.000 \\
.000\end{array}$ \\
\hline $\begin{array}{l}\text { 2. (Constant) } \\
\text { Intrinsic Religiosity } \\
\text { Extrinsic Religiosity }\end{array}$ & .048 & & .042 & $\begin{array}{l}.182 \\
-.138\end{array}$ & 8.945 & $<0.01$ & $\begin{array}{c}19.443 \\
3.510 \\
-2.650\end{array}$ & $\begin{array}{l}.000 \\
.001 \\
.008\end{array}$ \\
\hline
\end{tabular}

a. Dependent Variable: Organisational Involvement

b. Predictors in the model: (constant), Intrinsic religiosity

c. Predictors in the model: (constant), Intrinsic Religiosity, Extrinsic Religiosity

The result in Table 5 revealed that intrinsic and extrinsic religiosity jointly accounted for $3.7 \%$ variance in interpersonal relationship $\left(\mathrm{R}^{2}=.037, \mathrm{~F}(2,356)=6.872, \mathrm{p}<.01\right)$. However, intrinsic religiosity $(\beta=.136, \mathrm{p}<.01)$ and extrinsic religiosity 
$(\beta=.126, p<.01)$ were found to positively contribute to interpersonal relationship. This implies that one standard deviation increase in intrinsic religiosity and extrinsic religiosity will culminate in .136 and .126 (in standard deviation unit) increase in interpersonal relationship respectively.

Table 5: Stepwise regression analysis showing intrinsic religiosity and extrinsic religiosity interpersonal relationship

\begin{tabular}{lcccccccc}
\hline Model & $\boldsymbol{R}^{2}$ & $\Delta \mathbf{R}^{2}$ & $\begin{array}{c}\text { Adjusted } \\
\boldsymbol{R}^{2}\end{array}$ & $\boldsymbol{\beta}$ & $\mathbf{F}$ & $\mathbf{P}$ & $\mathbf{T}$ & Sig. \\
\hline 1. (Constant) & .021 & & .019 & .146 & 7.816 & & 9.607 & .000 \\
Intrinsic Religiosity & & & & & & $<.796$ & .005 \\
2. (Constant) & & .016 & & .136 & 6.072 & & 7.822 & .000 \\
$\begin{array}{l}\text { Intrinsic Religiosity } \\
\text { Extrinsic Religiosity }\end{array}$ & .037 & & .032 & .126 & & & 2.599 & .010 \\
\hline
\end{tabular}

a. Dependent Variable: Interpersonal Relationship

b. Predictors in the model: (constant), Intrinsic religiosity

c. Predictors in the model: (constant), Intrinsic Religiosity, Extrinsic Religiosity

\section{Discussion, Conclusion and Recommendation}

The result of this study revealed that intrinsic religiosity was the main predictor of organisational citizenship behaviours . This dimension of religiosity was found to positively contribute to the three dimensions of organisational citizenship behaviours. The implication is that employees' internalised values impacted on their demonstration of citizenship behaviours in the organisation. The result of this study suggested that the selfless nature of intrinsic religiosity impacted all the dimensions of OCB (both the behaviours targeted towards individuals within the organisation and those targeted towards the organisation as an entity). Likewise, McCrae (2002) linked religiosity with agreeableness which refers to selfless cooperation with others. Similarly, Barnard (1938) hinged employees' performance of OCB on their willingness to cooperate with co-workers and the organisation as a whole. The term "willingness" is influenced by some internal or intrinsic forces within the employees. These internal forces may include employees' beliefs and value system. Although several factors have been found to predict OCB but intrinsic religiosity also plays a significant role.

On the contrary, extrinsic religiosity inversely contributed to the dutifulness and organisational involvement dimensions of $\mathrm{OCB}$, while positively contributing to the interpersonal relationship dimension. This result has implication for the utilitarian nature of extrinsic religiosity. Extrinsically religious employees practice religiosity as a means to an end, therefore they may demonstrate the interpersonal dimension of OCB with the hope that such favours would be reciprocated in due time.

Extrinsically religious employees seek approval and other benefits from co-workers and superior officers, and so they act in ways that is pleasing to these individuals. In corroboration, Khalid et al (2013) found that intrinsic religiosity significantly predicted $\mathrm{OCBO}$ and extrinsic religiosity significantly predicted $\mathrm{OCBI}$. This confirms the claim that intrinsic religiosity involves selfless behaviours targeted towards corporate good; while extrinsic religiosity involves self-centered behaviours aimed at securing personal benefits for the extrinsically religious employees. In other words, extrinsically religious employees may be described as men pleasers; which explain the negative correlation between extrinsic religiosity and dutifulness, between extrinsic religiosity and organisational involvement, and the positive correlation between extrinsic religiosity and interpersonal relationship.

The dutifulness dimension of OCB involves undivided devotion to work and a passion for excellence in performance. This requires a lot of energy and commitment that is beyond the goad of an average employee. Therefore, the dutifulness dimension can only be sustained by the doggedness entrenched in employees' internalised values and principles. Like dutifulness, sustainable organisational involvement requires uninterrupted enthusiasm powered by deeprooted values and beliefs. Hence, the performance of dutifulness and organisational involvement may be difficult to maintain by extrinsically religious employees.

Spirituality may be viewed as synonymous with intrinsic religiosity. According to Milliman, Czaplewski and Ferguson (2003), a spiritual organization provides a platform for employees to satisfy their inner needs, contribute meaningfully to the advancement of the society, develop strong connections to others, and harmonize their core beliefs and values with those of the organization. While intrinsic religiosity enables the internalization of positive values and ethical behaviours at the individual level, workplace spirituality provide favourable environment for the demonstration of such personal values which ultimately results in citizenship behaviours and positive organisational outcome. In other 
words workplace spirituality provides a platform for concerted intrinsic religiosity that will promote the development of the qualities required for building successful organisations. For instance, Rastgar, et al (2012) associated workplace spirituality with such values as benevolence, generativity, humanism, integrity, justice, mutuality, receptivity, respect, responsibility and trust. These values are foundational to employees' demonstration of organisational citizenship behaviours.

This study concluded that intrinsic religiosity contributed positively to employees' demonstration of OCB; and that this dimension of religiosity may be related to workplace spirituality as both involve respect for personal and organisational values, meaning and purpose. Although several organisational, employee, task and leadership variables have been identified as antecedents of OCB, employees' emotional state, belief and value system also play crucial role in their work behaviours. It is therefore recommended that organisations should encourage intrinsic religiosity by incorporating spirituality into their corporate cultures. This means that organisations should engage in activities that would help employees harmonize their personal values with organisational values in the pursuit of improved productivity and excellence. For instance, Neck and Milliman (1994) noted that incorporating spirituality in corporate cultures would stimulate organisational commitment and improved performance among employees. Organisational cultures that breed workplace spirituality inspire employees to be truthful, to have a sense of security, and to be resourceful. In this type of culture, employees feel secured and free to explore their potentials in anticipation of equitable reward. Based on the reviewed literature (Milliman, et al, 2003; Neck \& Milliman, 1994; Rastgar, et al, 2012), this study suggests the following pragmatic steps to incorporate workplace spirituality into organisations' corporate cultures:

1. Mutual Responsibility

2. Organisational Receptivity

3. Mutual Trust and Integrity

4. Organisational Benevolence, empathy and employee welfare

5. Respect for employees

\subsection{Mutual Responsibility}

Organisations should encouraged shared responsibility for successes and failures with employees. Employees need to be motivated to see themselves as stakeholders in the organisation through participative decision making and equitable procedures and allocation of resources. A sense of mutual responsibility would propel employees to be open and receptive to organisational policies and strategies while also seeking innovative ways to improve their contributions to the success of the organisation without holding back any ounce of energy.

\subsection{Organisational Receptivity}

Organisations that aim to engage employees unreservedly must value the individual opinions of these employees and carefully select the most logical through active consultation. It is important that organisations inspire employees to think outside the box and provide ingenious strategies and pragmatic solutions to work challenges. Employees should be stimulated towards excellent performances through challenging work content and job design. This propels them to unleash their potentials and explore their inner virtues and skills.

\subsection{Mutual Trust and Integrity}

Organisations must demonstrate trust and belief in employees' abilities, capabilities and workplace conduct in order to foster openness and trust among employees. When employees have trust in the organisation, they feel secured and are able to freely express themselves and commit to the cause of the organisation. Organisations need to be fair and transparent in their policies, procedures and resource allocation in order to earn employees' trust and commitment.

\subsection{Organisational Benevolence, empathy and employee welfare}

Paramount in the quest of workplace spirituality is show of benevolence, empathy and concern for employees' welfare. Employees would give themselves wholly to their assignments when they trust that the organisation is seeking their welfare. Organisational benevolence is mostly reciprocated by employees who feel obliged to enthusiastically pursue the actualization of the corporate goals. 


\subsection{Respect for employees}

Organisations need to treat employees with respect and dignity in order to inspire wholehearted deliverables at work. Workplace spirituality is about sincerity and freedom to express and explore intrinsic potentials, virtues and values in the pursuit of corporate and personal advancement. Therefore, organisations should appreciate individual differences in their staff mix and treat each employee with dignity while valuing diversity. This will increase employees' self-worth and propel them to put unreserved energy into their assigned duties.

Workplace spirituality is founded on trust, benevolence, responsibility, integrity and sincerity. It describes a culture in which mutually responsible parties come together in the pursuit of a common goal without any iota of fear or doubt. Organisations are able to effectively harness the devoted efforts of their employees by creating the platform for them to unleash their full potentials.

\section{References}

Affeldt, D. L., \& MacDonald, D. A. (2010). The relationship of spirituality to work and organisational attitudes and behaviours in a sample of employees from a health care system. The Journal of Transpersonal Psychology, 42(2), 192-208.

Allameh, S. M., Amiri, S., \& Asadi, A. (2011). A survey of relationship between organisational commitments and organisational citizenship behaviour. Case study: Regional Water Organisation of Mazandaran Province. Interdisciplinary Journal of Contemporary Research in Business, 3(5), 360-368.

Allport, G., \& Ross, J.M. (1967). 'Personal religious orientation and prejudice', Journal of Personality and Social Psychology, 5, 432 443.

Bateman, T.S., \& Organ, D.W. (1983). Job satisfaction and the good soldier: The relationship between affect and employee citizenship. Academy of Management Journal, 26: 587-595.

Belogolovsky, E., \& Somech, A. (2010). Teachers' organisational citizenship behaviour: Examining the boundary between in-role behaviour and extra-role behaviour from the perspective of teachers, principals and parents. Teaching and Teacher Education 26, 914-923.

Farooqui, M.R. (2012). Measuring Organisational Citizenship Behaviour (OCB) as a consequence of Organisational Climate (OC). Asian Journal of Business Management, 4(3), 294-302.

Fernando, M., \& Jackson, B. (2006). The influence of religion-based workplace spirituality on business leaders' decision-making: An inter-faith study', Journal of Management and Organisation, 12 (1), 23-39.

Holdcroft, B.B.(2006). What is Religiosity? Catholic Education: A Journal of Inquiry and Practice, 10(1), 88-103.

Jahangir, N., Akbar, M.M., \& Haq, M. (2004). Organisational citizenship behaviour: Its nature and antecedents. BRAC University Journal, I (2),75-85.

Katz, D. (1964). "Motivational basis of organisational behaviour", Behavioural Science, 9, 131-146.

Katz, D., \& Kahn, R. L. (1966). The social psychology of organisations. New York: Wiley.

Khalid, S.A., Rahman, N.A., \& Madar, A.R.S. (2013). Undergraduates' Organisational Citizenship Behaviour: The Role of Religiosity. International Journal of Academic Research in Business and Social Sciences, 3(7), 574-584.

Khalid, S.A., Jusoff, H.K., Hassan, A., Ismail, M., Kassim, K. M., \& Rahman, N.A.(2009). Gender as a Moderator of the Relationship between OCB and Turnover Intention. Asian Social Science, 5(6), 108-117.

King, J.E., \& Williamson, O.I. (2005). "Workplace religious expression,religiosity, and job satisfaction: clarifying a relationship." Journal of Management, Spirituality, and Religion, 2, 173-198.

Kutcher, J.E., Bragger, J.D., Srednicki, R.O., \& Masco, L.L. (2010). The role of religiosity in stress, job attitudes, and organisational citizenship behaviour. Journal of Business Ethics, 95, 319-337.

Lee, K., \& Allen, N. J. (2002). Organisational citizenship behavior and workplace deviance: The role of affect and cognitions. Journal of Applied Psychology, 87(1), 131-142.

Marschke, E., Preziosi, R., \& Harrington, W.J.(2008). Professionals and executives support a relationship between organisational commitment and spirituality in the workplace. A paper submitted to the International Business \& Economics Research (IBER) Conference Las Vagas, September 29 - October 2.

McCrae, R. R. (2002). NEO-PI-R data from 36 cultures: Further Intercultural comparisons. In R. R. McCrae \& J. Alik. (Eds.), The FiveFactor model of personality across cultures (pp. 105-125). New York: Kluwer Academic Publisher.

McGhee, P., \& Grant, P. (2008). Spirituality and ethical behaviour in the workplace: Wishful thinking or authentic reality. Electronic Journal of Business Ethics and Organisation Studies, 13(2), 61-69.

Milliman, J., Czaplewski, A. J., \& Ferguson, J. (2003). Workplace spirituality and employee work attitudes: An exploratory empirical assessment. Journal of Organisational Change Management, 16(4), 426-47.

Mitroff, I. I., \& Denton, E. A. (1999). A study of spirituality in the workplace. Sloan Management Review, 40(4), 85-92.

Moore, T.W., \& Casper, W.J. (2006). An Examination of Proxy Measures of Workplace Spirituality: A Profile Model of Multidimensional Constructs. Journal of Leadership and Organisational Studies, 12(4), 109-118.

Neck, C. P., \& Milliman, J. F. (1994). Thought self-leadership: finding spiritual fulfilment in organisational life. Journal of Managerial Psychology, 9(6), 9-16. 
Obamiro, J. K., Ogunnaike, O. O., \& Osibanjo, O. A. (2014). Organisational Citizenship Behaviour, Hospital Corporate Image and Performance. Journal of Competitiveness, 6(1), $36-49$.

Olowookere, E.I. (2014). Organisational Citizenship Behaviours (OCB): A Key to Industrial Development in Nigeria. In D.O. Imhonopi \& U.M. Urim (Eds.), Trajectory to Industrial Development in Nigeria. (pp. 367-378). Ibadan: Cardinal Prints.

Olowookere, E.I. \& Adejuwon, G.A (2015). Development and validation of Organisational Citizenship Behaviours Scale (OCBS) for the Nigerian context. Psychology, 6 (05), 533-539.

Organ, D.W. (1988). Organisational citizenship behaviour: The Good Soldier Syndrome. Lexington Books, Lanham, MA.

Organ, D.W. (1990). The motivational basis of organisational citizenship behaviour. In Staw, B. W. Staw \& L. L. Cummings (Eds.), Research in Organisational Behaviour, 12 (pp. 43-72), JAI Press, Greenwich, CT.

Othman, R., \& Hariri, H. (2012). Conceptualizing religiosity influence on whistle-blowing intentions. British Journal of Economics, Finance and Management Sciences, 6 (1), 62-92.Ouchi, W.G. (1981). Theory Z. New York: Avon Books.

Park J. Z., \& Smith, C. (2000). To whom much has been given...: Religious capital and community voluntarism among churchgoing protestants. Journal for the Scientific Study of Religion, 39, 272-286.

Rastgar, A. A., Zarei, A., Davoudi, S. M. M., \& Fartash, K. (2012). The link between workplace spirituality, organisational citizenship behavior and job performance in Iran. Arth Prabhand: A Journal of Economics and Management, 1(6), 51-67.

Roundy, P.T. (2009). Work and Religion: Artificial Dichotomy or Competing Interests? International Journal of Human and Social Sciences, 4(5), 311-317.

Smith, C.A., Organ, D.W., \& Near, J.P. (1983). "Organisational citizenship behaviour: Its nature and antecedents", Journal of Applied Psychology, 68, 653-663.

Ueda,Y. (n.d). Organisational citizenship behaviour in a Japanese organisation: The effects of job involvement, organisational commitment, and collectivism. Journal of behavioural Studies in Business, 1-14.

Weaver, G., \& Agle, B. (2002). Religiosity and ethical behaviour in organisational: A symbolic integrationist perspective. Academy of Management Review, 27 (1), 77-97.

William, L.J., \& Anderson, S.E. (1991). Job satisfaction and organisational commitment as predictors of organisational citizenship and inrole behaviours. Journal of Management, 17(3), 601-617. 